\title{
Japanese Tooth Size: Past and Present
}

\author{
C. L. BRACE AND MASAFUMI NAGAI \\ Museum of Anthropology, University of Michigan, University Museums \\ Building, Ann Arbor, Michigan 48109 (C.L.B.), and Department of Anatomy, \\ School of Medicine, Kyushu University, Fukuoka-shi (M.N.)
}

\author{
KEY WORDS Teeth, Japan, Asia
}

\begin{abstract}
Mesial-distal and buccal-lingual crown measurements were made on male and female samples of recent Japanese teeth from three locations, Fukuoka, Kyoto, and Tokyo, and for Hokkaido Ainu and Koreans. Similar data were collected for prehistoric Middle-to-Late Jomon Japanese and from Yayoi specimens representing the first agriculturalists to appear in Japan. From a tooth-bytooth comparison of cross-sectional areas, it was shown that the modern Japanese samples did not differ from one part of Japan to another. Korean tooth size also is not significantly different from Japanese, while Ainu have the smallest teeth recorded in Asia. The Yayoi who brought rice to Japan about 300 B.C. came in with teeth that were the same size as Chinese Neolithic teeth. They encountered a resident Jomon population whose teeth were $10 \%$ smaller. From tooth size measures alone, it is most economical to suggest that, if the rates of reduction observed elsewhere in the world applied in Japan, the recent Ainu would best be regarded as the direct descendants of the Jomon, while the modern Japanese are the results of in situ reduction from the incoming Yayoi. Other aspects of craniofacial morphology suggest that some Jomon was incorporated by the Yayoi. The modern Japanese, then, while predominantly derived from the Yayoi, would include a Jomon component.
\end{abstract}

Late- and Post-Pleistocene reductions in muscularity and robustness can be documented in virtually every part of the world where human populations have remained in situ and maintained their continuity up into historical times. Because of the ease of quantification and the sheer amount of data available, the most easily demonstrated of these reductions is the one that can be seen in the human dentition. Since more attention has been focused on Europe than anywhere else, it has produced the most complete and unequivocal evidence for this trend of dental reduction (Brace, 1977, 1979; Frayer, 1978). Where the evidence has been examined, however, it is apparent that parallel reductions have taken place in other regions, for example preEuropean North America (Brace and Mahler, 1971), the Near East (Smith, 1977), China (Brace et al., in press), Southeast Asia (Brace and Vitzthum, in press), and even Australia (Brace, 1980).

The magnitude of the change in tooth size is impressive to say the least, with a drop of some $50 \%$ since the early Mousterian in Europe
(Brace, 1979), but, because of problems in establishing precise dates for some prehistoric samples, there is less certainty about the rates of change. Similarly, it is not yet clear whether the changes have followed the path of phyletic gradualism or punctuated equilibria (Brace, 1981), although we would suggest that the evidence for gradual and continuous change is more convincing than the converse. It is abundantly clear, however, that reduction did not stop nor was stasis achieved with the first appearance of "modern" Homo sapiens more than 30,000 years ago. Instead, tooth size continued to drop by more than $20 \%$ through the Mesolithic, the Neolithic and up to the present. In the latter part of this time span, it would appear that the rate of change accelerated to more than 1\% per thousand years (Brace, 1979).

The evolutionary mechanism which has produced the observed change has been the subject of continuing differences of opinion (Brace, 1963, 1980; Brace and Ryan, 1980; Brace et al., in

Received April 19, 1982; accepted June 29, 1982 
press; Armelagos and Van Gerven, 1980; Frayer, 1978; Smith, 1976, 1977; Williams, 1978), and we do not intend to dwell on the controversy here. It is relevant to our present concern, however, to note that the argument relating reduction to selective force relaxation leads to various predictions that can be tested against the data available in Japan. Specifically, it has been suggested that the use of pottery in the preparation of food brought about a major relaxation of the selective forces that had previously served to maintain a functional dentition throughout life (Brace and Mahler, 1971). The prediction follows, then, that dental reduction should be most apparent in the people who have continued to inhabit the areas where pottery has been in use for the longest period of time. Since Jomon pottery in Japan goes back further in time (i.e., 12,500 B.P. at Fukui Cave in Kyushu) than any other known tradition in the world (Ikawa-Smith, 1976, 1978, 1980; Pearson, 1977), it should be associated with people who show a maximum degree of dental reduction, at least when compared with their counterparts in adjacent parts of Asia.

In this paper, we present the data for tooth size in modern and prehistoric Japan. These are compared with the data available for other recent and prehistoric Asian samples, and we consider what light this can shed on questions concerning the origin and shaping of modern Japanese form.

\section{MATERIALS AND METHODS}

Mesial-distal and buccal-lingual crown measurements were taken to the nearest $0.1 \mathrm{~mm}$ according to the conventions usually followed in dental anthropology (Brace, 1979). Although previous studies have reported on both modern and prehistoric Japanese dental measurements, they have been done by separate authors, fewer examples were treated, and the modern specimens did not represent the geographic spectrum of Japan (Miyabara, 1916; Yamada, 1932; Gonda, 1959; Hanihara, 1976, 1977). The tooth measurements reported here were all made by the senior author in September and October of 1980 . If nothing else, the present work should at least have the merit of consistency of technique.

As in previous studies (Brace, 1978, 1979, 1980; Brace and Hinton, 1981; Brace, Mahler, and Rosen, 1973; Brace and Ryan, 1980; Brace et al., in press; Brace and Vitzthum, in press), teeth were not measured if it was apparent that wear had made an appreciable alteration in crown size. Buccal-lingual measurements, which are taken relatively low on the crown, are less likely to be affected by wear than are mesial-distal measurements. The latter are especially affected by interproximal attrition (Brace, 1967; Wolpoff, 1971). As a consequence, one might think that the most effective comparisons would be made by using buccal-lingual measurements alone. Experience has shown, however, that the clearest group distinctions are made by using the mesial-distal and buccal-lingual measurements in combination (Brace, 1967; Brace, Mahler, and Rosen, 1973). Their product can be taken as a representation of cross-sectional area. If selection really does operate to maintain usable tooth substance, then given the impractability of measuring unworn crown height, the closest approximation to the trait which selection actually controls is represented by cross-sectional area (Brace, 1967, 1980).

The data on which our comparisons are based are recorded in Tables 1 to 7 . We only used individuals for which sexual identification could be made. For each individual used, both right and left teeth were measured when possible, and an average of the two was taken to represent that individual. Of course if only one side was measurable, that is what was used. In either case, the resultant figure was considered as a single instance for the subsequent calculation of sample statistics. These dimensions were treated in a number of ways to simplify what would otherwise have been an unmanageable number of separate figures.

First, we multiplied the mesial-distal (MD) and buccal-lingual (BL) figures together to ap-

TABLE 1. Mesio-distal and buccal-lingual measurements standard deviations, and $n$ for female and male human teeth from the Edo period in Tokyo

\begin{tabular}{|c|c|c|c|c|c|c|c|c|c|c|}
\hline & \multicolumn{5}{|c|}{ Female } & \multicolumn{5}{|c|}{ Male } \\
\hline & MD & $\mathrm{sd}$ & BL & sd & $\mathbf{n}$ & MD & $\mathrm{sd}$ & $\mathrm{BL}$ & sd & $\mathbf{n}$ \\
\hline $\mathbf{I}^{1}$ & 8.3 & 0.1 & 7.0 & 0.4 & 2 & 8.2 & 0.5 & 7.4 & 0.4 & 2 \\
\hline $\mathrm{I}^{2}$ & 6.7 & - & 6.3 & - & 1 & 6.8 & 0.9 & 6.5 & 0.6 & 11 \\
\hline$C$ & 7.9 & 0.4 & 8.6 & 0.6 & 5 & 7.7 & 0.6 & 8.5 & 0.7 & 25 \\
\hline $\mathrm{P}^{1}$ & 7.4 & 0.5 & 9.5 & 0.5 & 10 & 7.2 & 0.4 & 9.6 & 0.6 & 35 \\
\hline $\mathrm{P}^{2}$ & 6.8 & 0.4 & 9.2 & 0.5 & 13 & 6.9 & 0.4 & 9.5 & 0.6 & 43 \\
\hline $\mathbf{M}^{1}$ & 10.4 & 0.7 & 11.4 & 0.7 & 21 & 10.5 & 0.6 & 11.6 & 0.5 & 64 \\
\hline $\mathbf{M}^{2}$ & 9.9 & 0.7 & 11.5 & 1.0 & 21 & 10.0 & 0.5 & 11.7 & 0.6 & 52 \\
\hline $\mathbf{M}^{3}$ & 9.7 & 0.2 & 11.6 & 0.7 & 4 & 9.5 & 1.2 & 11.3 & 0.8 & 25 \\
\hline$I_{1}$ & 5.0 & - & 5.1 & - & 1 & 4.9 & 0.8 & 5.7 & 0.4 & 3 \\
\hline $\mathrm{I}_{2}$ & 5.6 & - & 5.8 & - & 1 & 5.8 & 0.9 & 6.4 & 0.5 & 5 \\
\hline $\mathrm{C}$ & 6.4 & 0.4 & 7.2 & 0.2 & 4 & 6.7 & 0.5 & 7.7 & 0.7 & 11 \\
\hline$P_{1}$ & 6.8 & 0.5 & 7.4 & 0.5 & 6 & 7.2 & 0.4 & 8.0 & 0.6 & 28 \\
\hline$P_{2}$ & 6.9 & 0.6 & 8.1 & 0.6 & 9 & 7.3 & 0.4 & 8.4 & 0.5 & 20 \\
\hline $\mathbf{M}_{1}$ & 11.1 & 1.0 & 10.7 & 0.7 & 19 & 11.5 & 0.7 & 11.0 & 0.5 & 41 \\
\hline $\mathbf{M}_{2}$ & 10.9 & 0.9 & 10.4 & 0.8 & 16 & 11.3 & 0.8 & 10.6 & 0.5 & 34 \\
\hline $\mathrm{M}_{3}$ & 10.5 & 0.8 & 9.9 & 0.8 & 7 & 10.7 & 0.8 & 10.1 & 0.6 & 25 \\
\hline
\end{tabular}


TABLE 2. Mesial-distal and buccal-lingual measurements standard deviations, and $n$ for female and male human teeth from Kyoto

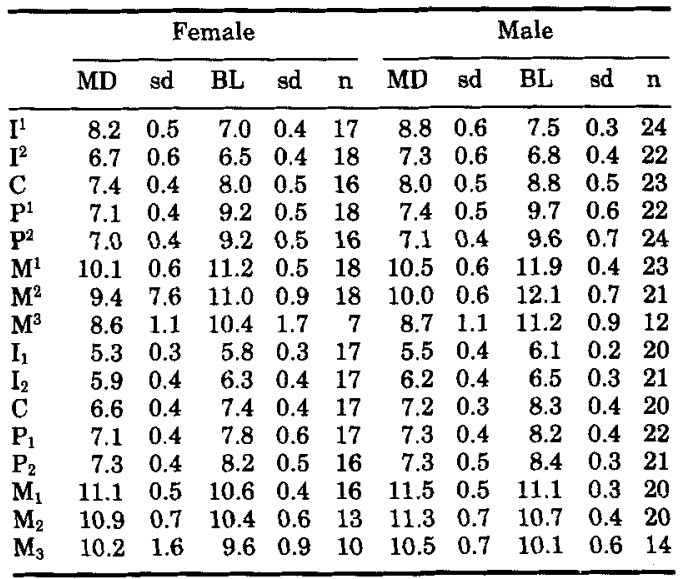

TABLE 3. Mesial-distal and buccal-lingual measurements standard deviations, and $n$ for female and male human teeth from Fukuoka

\begin{tabular}{|c|c|c|c|c|c|c|c|c|c|c|}
\hline & & & imale & & & & & Male & & \\
\hline & $\mathrm{MD}$ & $s d$ & BL & sd & $\mathrm{n}$ & MD & sd & BL & sd & $\mathbf{n}$ \\
\hline $\mathrm{I}^{1}$ & 8.5 & 0.4 & 7.4 & 0.5 & 7 & 8.5 & 0.4 & 7.4 & 0.2 & 5 \\
\hline $\mathrm{I}^{2}$ & 6. & 1.0 & 6.3 & 0.8 & 7 & 6.8 & 0.5 & 6.4 & & 6 \\
\hline C & 7.6 & 0.2 & 8.2 & 0.6 & 8 & 7.6 & 0.5 & 8.3 & 0.5 & 5 \\
\hline $\mathrm{P}^{1}$ & 7.2 & 0.4 & 9.3 & 0.6 & 8 & 7.3 & 0.3 & 9.4 & 0.2 & 5 \\
\hline $\mathrm{P}^{2}$ & 6.8 & 0.4 & 9.0 & 0.6 & 8 & 7.1 & 0.3 & 9.4 & 0.5 & 4 \\
\hline $\mathrm{M}^{1}$ & 10.5 & 0.4 & 11.5 & 0.4 & 8 & 10.1 & 0.4 & 11.6 & 0.5 & 5 \\
\hline $\mathbf{M}^{2}$ & 9.8 & 0.6 & 11.2 & 0.6 & 9 & 10.0 & 0.4 & 11.7 & 0.5 & \\
\hline $\mathbf{M}^{3}$ & 8.4 & 1.7 & 9.8 & 2.2 & 2 & 8.0 & - & 12.2 & - & \\
\hline$I_{1}$ & 5 & 0.1 & 6.0 & 0.4 & 7 & 5.3 & 0.2 & 6.0 & 0.4 & \\
\hline $\mathbf{I}_{2}$ & 6.0 & 0.3 & 6.5 & 0.4 & 7 & 5.9 & 0.3 & 6.4 & 0.3 & \\
\hline C & 6.8 & 0.4 & 7.6 & 0.6 & 7 & 7.0 & 0.4 & 7.9 & 0.2 & \\
\hline$P_{1}$ & 7.2 & 0.4 & 8.0 & 0.6 & 8 & 7.1 & 0.2 & 7.8 & 0.2 & \\
\hline $\mathbf{P}_{2}$ & 7.1 & 0.5 & 8.0 & 0.5 & 7 & 7.3 & 0.3 & 8.1 & 0.6 & \\
\hline $\mathbf{M}_{1}$ & 11.4 & 0.6 & 10.9 & 0.5 & 8 & 11.1 & 0.3 & 11.1 & 0.7 & \\
\hline $\mathbf{M}_{2}$ & 11.0 & 0.5 & 10.4 & 0.5 & 9 & 11.4 & 0.6 & 11.1 & 0.2 & \\
\hline $\mathbf{M}_{3}$ & 10.6 & 1.3 & 9.9 & 1.0 & 4 & 9.2 & - & 10.7 & - & \\
\hline
\end{tabular}

proximate cross-sectional areas. Not only does this reduce the number of separate figures, but it also enables us to deal with something that is closer to the trait on which selection operates than would be the case if we were to focus on each dimension separately. Next, we added the male to the female cross-sectional area and divided by two, tooth by tooth, to obtain a usable mean figure for each tooth category. Finally, we simply added the mandibular to the maxillary cross-sectional area for each tooth category separately to produce composite crosssectional areas for each of the eight tooth categories.
TABLE 4. Mesial-distal and buccal-lingual measurements standard deviations, and $n$ for female and male Ainu teeth

\begin{tabular}{|c|c|c|c|c|c|c|c|c|c|c|}
\hline & \multicolumn{5}{|c|}{ Female } & \multicolumn{5}{|c|}{ Male } \\
\hline & MD & sd & BL & sd & $\mathbf{n}$ & MD & sd & BL & sd & $\mathrm{n}$ \\
\hline$I^{1}$ & 7.8 & 0.2 & 6.6 & 0.4 & 4 & 8.0 & 0.5 & 6.8 & 0.2 & 6 \\
\hline$I^{2}$ & 6.9 & 0.3 & 6.2 & 0.3 & 6 & 6.8 & 0.5 & 6.2 & 0.3 & 5 \\
\hline C & 7.6 & 0.4 & 7.3 & 0.5 & 9 & 7.4 & 0.3 & 7.8 & 0.2 & 8 \\
\hline $\mathbf{P}^{1}$ & 6.8 & 0.3 & 8.8 & 0.5 & 10 & 6.8 & 0.4 & 9.0 & 0.6 & 13 \\
\hline $\mathrm{P}^{2}$ & 6.2 & 0.3 & 8.4 & 0.5 & 15 & 6.5 & 0.5 & 8.7 & 0.7 & 14 \\
\hline $\mathbf{M}^{1}$ & 10.0 & 0.4 & 10.9 & 0.4 & 20 & 10.0 & 0.5 & 11.3 & 0.5 & 22 \\
\hline $\mathbf{M}^{2}$ & 9.2 & 0.4 & 10.5 & 0.8 & 12 & 9.4 & 0.7 & 11.1 & 0.6 & 18 \\
\hline $\mathbf{M}^{3}$ & 8.6 & 0.7 & 10.1 & 0.7 & 9 & 8.8 & 0.4 & 10.6 & 0.4 & 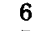 \\
\hline $\mathrm{I}_{1}$ & 4.8 & 0.4 & 5.1 & 0.1 & 2 & 5.2 & 0.2 & 5.7 & 0.2 & \\
\hline $\mathrm{I}_{2}$ & 5.5 & 0.2 & 5.6 & 0.5 & 3 & 5.6 & 0.2 & 5.9 & 0.2 & 9 \\
\hline C & 6.5 & 0.3 & 6.9 & 0.5 & 6 & 6.5 & 0.4 & 7.3 & 0.3 & 11 \\
\hline$P_{1}$ & 6.6 & 0.4 & 6.9 & 0.5 & 6 & 6.5 & 0.3 & 7.3 & 0.5 & 12 \\
\hline $\mathbf{P}_{2}$ & 6.5 & 0.2 & 7.5 & 0.4 & 9 & 6.8 & 0.5 & 7.9 & 0.5 & 14 \\
\hline $\mathbf{M}_{1}$ & 10.7 & 0.4 & 10.4 & 0.5 & 14 & 11.1 & 0.6 & 11.0 & 0.6 & 14 \\
\hline $\mathrm{M}_{2}$ & 10.0 & 0.5 & 9.7 & 0.6 & 11 & 10.5 & 0.5 & 10.1 & 0.5 & 12 \\
\hline $\mathbf{M}_{3}$ & 9.7 & 0.6 & 9.2 & 0.4 & 8 & 10.2 & 0.4 & 9.6 & 0.4 & 9 \\
\hline
\end{tabular}

TABLE 5. Mesial-distal and buccal-lingual measurements standard deviations, and $n$ for female and male Korean teeth

\begin{tabular}{|c|c|c|c|c|c|c|c|c|c|c|}
\hline & & & male & & & & & Male & & \\
\hline & MD & sd & BL & sd & $\mathbf{n}$ & MD & sd & BL & sd & $\mathbf{n}$ \\
\hline$I^{1}$ & 8.4 & 0.1 & 7.3 & 0.2 & 2 & 8.7 & 0.3 & 7.6 & 0.4 & 12 \\
\hline$I^{2}$ & 6. & 0.5 & 6.4 & 0. & & 3 & 0.4 & 6.9 & 0.5 & 11 \\
\hline C & 7.7 & 0.3 & 8.0 & 0.6 & 9 & 7.9 & 0.4 & 8.7 & 0.8 & 16 \\
\hline $\mathbf{P}^{1}$ & 7.2 & 0.3 & 9.2 & 0.4 & 12 & 7.3 & 0.4 & 9.6 & 0.7 & 24 \\
\hline $\mathbf{P}^{2}$ & 6.9 & 0.3 & 9.2 & 0.6 & 9 & 6.9 & 0.4 & 9.6 & 0.6 & 23 \\
\hline $\mathbf{M}^{1}$ & 10.1 & 0.4 & 11.5 & 0.5 & 14 & 10.2 & 0.5 & 11.6 & 0.5 & 30 \\
\hline $\mathbf{M}^{2}$ & 9.6 & 0.5 & 11.3 & 0.6 & 14 & 9.8 & 0.5 & 11.8 & 0.7 & 30 \\
\hline $\mathbf{M}^{3}$ & 9.0 & 0.5 & 11.4 & 0.5 & 2 & 8.8 & 0.4 & 11.0 & 0.8 & 12 \\
\hline $\mathrm{I}_{1}$ & 5.4 & 0.2 & 5.6 & 0.2 & 4 & 6.5 & 0.3 & 6.2 & 0.4 & 11 \\
\hline $\mathbf{I}_{2}$ & 5.9 & 0.3 & 6.2 & 0.0 & 5 & 6.2 & 0.2 & 6.7 & 0.4 & 10 \\
\hline C & 6.8 & 0.2 & 7.6 & 0.3 & 5 & 7.0 & 0.4 & 8.3 & 0.4 & 11 \\
\hline $\mathbf{P}_{1}$ & 7.2 & 0.1 & 8.0 & 0.4 & 4 & 7.3 & 0.4 & 8.3 & 0.6 . & 10 \\
\hline$P_{2}$ & 7.3 & 0.2 & 8.4 & 0.4 & 4 & 7.1 & 0.4 & 8.5 & 0.5 & 12 \\
\hline $\mathbf{M}_{1}$ & 11.0 & 0.4 & 10.7 & 0.5 & 6 & 11.4 & 0.5 & 11.2 & 0.4 & 13 \\
\hline $\mathbf{M}_{2}$ & 10.7 & 0.8 & 10.4 & 0.5 & 6 & 11.3 & 0.4 & 10.8 & 0.6 & 13 \\
\hline $\mathbf{M}_{3}$ & 9.9 & 1.1 & 9.7 & 0.5 & 6 & 11.0 & 0.6 & 10.4 & 0.7 & 9 \\
\hline
\end{tabular}

The modern Fukuoka sample was taken from the dissecting room collection assembled by Prof. Takeo Kanaseki, and is currently housed in the Department of Anatomy at the Kyushu University Medical School. Identification of sex was based on the records of the collection.

The modern Kyoto sample was taken from the dissecting room collection assembled by the late Prof. Kiyono of the Department of Anatomy at Kyoto University, and is currently housed in the Laboratory of Physical Anthropology at Kyoto University. Again, sexual identification was made on the basis of positive records. 
TABLE 6. Mesial-distal and buccal-lingual measurements standard deviations, and $n$ for Jomon female and male teeth

\begin{tabular}{|c|c|c|c|c|c|c|c|c|c|c|}
\hline & \multicolumn{5}{|c|}{ Female } & \multicolumn{5}{|c|}{ Male } \\
\hline & $\mathrm{MD}$ & sd & BL, & sd & $\mathbf{n}$ & MD & sd & BL & sd & $\mathbf{n}$ \\
\hline $\mathrm{I}^{1}$ & 8.2 & 0.4 & 6.9 & 0.4 & 16 & 8.4 & 0.5 & 7.2 & 0.4 & \\
\hline $\mathrm{I}^{2}$ & 6.7 & 0.4 & 6.4 & 0.4 & 17 & .0 & 0.5 & 6.7 & 0.5 & \\
\hline C & 7.0 & 0.4 & 7.4 & 0.5 & 14 & .6 & 0.4 & 8.1 & 0.4 & \\
\hline $\mathbf{P}^{1}$ & 6.6 & 0.4 & 9.0 & 0.6 & 34 & 6.9 & 0.4 & 9.3 & 0.5 & \\
\hline $\mathrm{p}^{2}$ & 6.2 & 0.4 & 8.8 & 0.5 & 43 & 6.4 & 0.4 & 9.0 & 0.6 & \\
\hline $\mathbf{M}^{1}$ & 9.8 & 0,5 & 11.3 & 0.5 & 43 & 10.1 & 0.5 & 11.7 & 0.5 & \\
\hline $\mathbf{M}^{2}$ & 9.0 & 0.5 & 10.9 & 0.6 & 34 & 9.3 & 0.5 & 11.3 & 0.6 & \\
\hline $\mathbf{M}^{3}$ & 8.3 & 1.0 & 10.3 & 1.2 & 25 & 8.5 & 0.7 & 10.8 & 0.8 & \\
\hline$I_{3}$ & 5.1 & 0.3 & 5.6 & 0.3 & 14 & 5.2 & 0.3 & 5.9 & 0.3 & \\
\hline $\mathrm{I}_{2}$ & 5.6 & 0.3 & 6.0 & 0.3 & 19 & 5.8 & 0.3 & 6.2 & 0.3 & \\
\hline C & 6.4 & 0.2 & 7.1 & 0.4 & 25 & 6.7 & 0.4 & 7.5 & 0.4 & \\
\hline$P_{1}$ & 6.6 & 0.4 & 7.5 & 0.4 & 39 & 6.8 & 0.4 & 7.7 & 0.4 & \\
\hline$P_{2}$ & 6.7 & 0.5 & 7.9 & 0.6 & 53 & 6.8 & 0.4 & 8.2 & 0.5 & \\
\hline $\mathbf{M}_{1}$ & 11.1 & 0.6 & 10.9 & 0.5 & 57 & 11.4 & 0.6 & 11.3 & 0.5 & \\
\hline $\mathbf{M}_{2}$ & 10.4 & 0.7 & 10.1 & 0.5 & 61 & 10.8 & 0.6 & 10.5 & 0.4 & \\
\hline $\mathrm{M}_{3}$ & 10.2 & 0.9 & 9.7 & 0.7 & 44 & 10.6 & 0.8 & 10.1 & 0.6 & 71 \\
\hline
\end{tabular}

TABLE 7. Mesial-distal and buccal-lingual measurements standard deviations, and $n$ for Yayoi female and male teeth

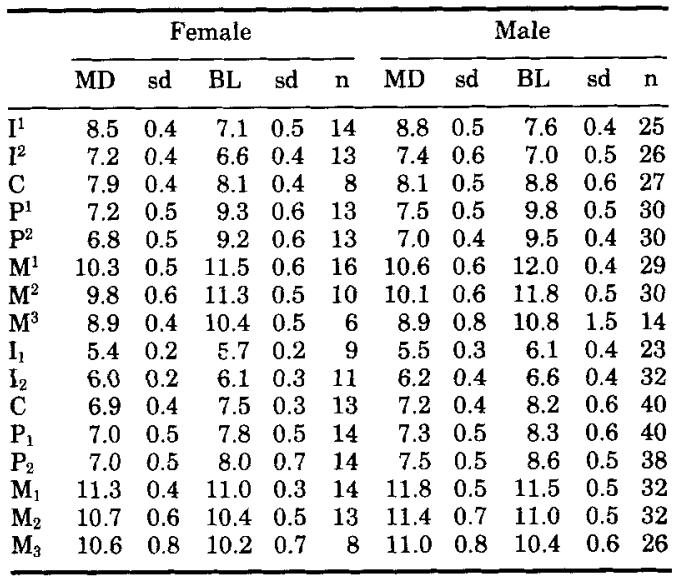

The sample labeled Edo was largely from Edo Period (1603-1868) (Befu, 1971) burial grounds that were preempted by the growth of the modern city of Tokyo. Some specimens were from other localities in the northeastern end of Honshu. These are now housed in the University Museum at the University of Tokyo. Assessment of sex was made by the senior author.

The Ainu sample was combined from the specimens collected in Hokkaido during the 1920 s by the late Prof. Kiyono of Kyoto, and from specimens collected in 1888 and 1889 from Hokkaido by the late Prof. Koganei of the Department of Anatomy at the University of Tokyo Medical School (Koganei, 1894). The Kiyono collection is in the Laboratory of Physical Anthropology at Kyoto University, and the Koganei collection is in the Department of Anatomy at the University of Tokyo. Assessment of sex was made by the senior author.

The Korean sample is made up principally of Koreans who were residents of Japan; so no real association with different parts of Korea was possible. The bulk of the sample came from Prof. Koganei's collection in Tokyo, and Prof. Kiyono's dissecting room collection in Kyoto, although he had actually excavated some from various burial sites in Korea. The remainder was from Prof. Kanaseki's dissecting room collection in Fukuoka.

The Jomon sample, representing the preagricultural population of Japan, includes material stored in the Laboratory of Physical Anthropology at Kyoto University, in the University Museum at the University of Tokyo, and in the National Museum of Science in Tokyo. There were not enough Early Jomon specimens for calculating usable mean figures. Instead, our sample consisted of Middle Jomon specimens (principally from the Ota (Ohta) shell mound in Hiroshima Prefecture, and the Ataka shell mound in Kumamoto Prefecture now stored in Kyoto), and more Late and Latest Jomon material (especially from the Tsukumo site in western Honshu and the Yoshigo shell mound near Nagoya, now stored in Kyoto), and from the Ubayama site near Ichikawa City not far from Tokyo, plus some other small collections now in Tokyo (Kintaka, 1928). Identification of sex was made by the senior author aided by associated postcranial skeletal remains.

The Yayoi sample, representing the rice cultivators who appeared in western Japan from Korea in the third century B.C. (Semba, 1960; Befu, 1971; Ikawa-Smith, 1980), is from the southwestern end of the island of Honshu, and the northern and western parts of Kyushu, especially the Doigahama site in Yamaguchi Prefecture and the Mitsu-Nagata site in Saga Prefecture (Kanaseki and Kai, 1955; Kanaseki et al., 1960; Ushijima, 1954; Ono, 1957; Sanui, 1960). These are stored in the collections of the Department of Anatomy at Kyushu University. Identification of sex was made by the second author with the aid of postcranial skeletal material. 


\section{RESULTS}

The results for the material reported here are recorded in Table 8. To make comparisons even more convenient, the composite cross-sectional areas for each group were summed to produce a single summary tooth size (TS) figure. This is recorded in the last row of Table 8.

Although comparisons using TS figures are easy to visualize and lend themselves to graphic treatment of considerable numbers of samples, the lack of a variance figure means that we cannot use conventional statistics. This problem has been dealt with elsewhere based on the few groups where a variance for TS could in fact be calculated (Brace, 1980). It is this which leads us to suspect that TS differences in the neighborhood of $50 \mathrm{~mm}^{2}$ are probably significant, and differences of $100 \mathrm{~mm}^{2}$ almost certainly express meaningful biological differences between the groups being compared.

By using nonparametric statistics, the set of composite cross-sectional areas for one group can be compared with that from any other group and, even in the absence of variance figures, a probability level can be determined for the observed difference. For example, the composite areas for each modern Japanese sample can be compared with each other modern Japanese sample by using the Wilcoxon matched-pairs signed-ranks test. Since there is no significant difference between our modern groups, this allows us to construct a single set by averaging the three samples. This is recorded in the last column of Table 8 , and we can regard it as a mean representation of tooth size in modern Japan.

In the same fashion, it can be shown that the Korean sample is not significantly different from the Japanese mean. When we turn to the other three groups, however, significant differences are clearly apparent. Both the Yayoi and the Ainu samples are significantly
$(<0.01)$ different from all the others. The Jomon sample differs from the modern Japanese at a level which approaches significance $(0.05>0.02)$.

These probability levels were calculated assuming two-tailed logic. If, however, we use one-tailed logic, the probability levels are even higher. For example, if we ask whether the Yayoi sample is not just different, but whether it is larger than the others, then we can note that it is larger with a probability of $<0.001$ that such a difference could occur by chance alone. Likewise, if we suspect that the Ainu teeth are not just different, but smaller than all of the other samples, then we can note that they are indeed smaller and that there is less than a 0.001 probability that the difference is the result of mere chance.

In comparing our various Jomon samples, we could find no clear evidence of a tooth size trend through time, although this may just be because of the small numbers of earlier specimens. In addition, at the time the material was excavated, it was less possible to assign precise levels of antiquity to the material discovered than it would be using current knowledge and techniques, and there is a chance that our Middle and Late Jomon samples may actually be very close together in time. It is our impression, however, that, aside from the dentition, there is a clear reduction in the average amount of skeletal robustness from Early to Middle to Late Jomon.

\section{DISCUSSION}

There are some fascinating parallels in the comparison of the indigenes of the major island groups at both the northeastern and northwestern margins of the Eurasian land mass, namely in the Japanese archipelago and the British Isles. Both areas have been inhabited since before the beginning of what in the West is called the Upper Palaeolithic. In Japan it is

TABLE 8. Composite cross-sectional areas in square millimeters

\begin{tabular}{|c|c|c|c|c|c|c|c|c|}
\hline & Yayoi & Jomon & Ainu & Korea & Fukuoka & Kyoto & Edo & Japan Mean \\
\hline II & 96.2 & 94.8 & 80.0 & 96.1 & 97.6 & 94.4 & 86.2 & 92.7 \\
\hline I2 & 88.5 & 80.1 & 74.4 & 85.3 & 82.4 & 85.6 & 78.0 & 82.0 \\
\hline C & 122.8 & 104.6 & 102.7 & 120.1 & 116.8 & 119.8 & 116.0 & 117.5 \\
\hline P1 & 128.6 & 113.4 & 107.0 & 127.3 & 124.4 & 126.7 & 124.7 & 125.3 \\
\hline P2 & 125.3 & 110.6 & 105.6 & 125.6 & 121.8 & 127.5 & 123.5 & 124.3 \\
\hline M1 & 252.8 & 240.1 & 227.7 & 239.4 & 248.9 & 242.2 & 243.8 & 245.0 \\
\hline M2 & 234.0 & 211.8 & 202.0 & 228.6 & 238.8 & 230.6 & 233.3 & 234.2 \\
\hline M3 & 206.6 & 193.2 & 183.6 & 204.9 & 193.1 & 196.8 & 219.6 & 203.2 \\
\hline TS & 1255 & 1149 & 1083 & 1227 & 1224 & 1224 & 1225 & 1224 \\
\hline
\end{tabular}


called the Late Paleolithic (Ikawa-Smith, 1980). Both areas were invaded by grain cultivators well after agriculture had been established on the adjacent mainlands, and both today are characterized by languages whose vocabularies are made up of large percentages of words from sources that are either entirely unrelated or genetically distant. English, for example, remains a Germanic language, although French and Latin have contributed a large Romance language component to its vocabulary. Japanese for its part remains an Altaic language, even though at least half its vocabulary is of Chinese origin (Miller, 1967, 1971, 1974; Chew, 1978). Both areas, as befits their ecological setting, make extensive use of fish as a staple food, although in one instance it is regularly plunged into heated grease and in the other it tends not to be cooked at all. Both maintain a tradition of having successfully resisted invasion for a prolonged period of history. Both also remain the two major parts of the world where custom dictates that one drives on the left-hand side of the road, but this is a very recent peculiarity that is less clearly related to the processes that have contributed to the subject of our concern in the present paper.

\section{Jomon or Yayoi as ancestors?}

We began this paper by noting that dental reduction has occurred in virtually every human population for which we have records that extend back two to four thousand years or more. In Japan, however, the matter is not quite so straightforward. Although Japan has been inhabited since well back into the Pleistocene, there remains the question of whether the Lateand Post-Pleistocene people are the sole ancestors of the modern Japanese. If the Jomon people became transformed into modern Japanese in situ, this, as Suzuki has recognized (1969), would be the only known instance where an actual increase in tooth and face size has occurred. The increase would be about $14 \%$, which is approximately double what the decrease amounts to in England, France, and southern China since the Neolithic (Brace, 1979; Brace et al., in press). From other work (Yamaguchi, in press), it is apparent that body size certainly did not increase through time. The tooth size change, then, cannot be accounted for by correlation with a general change in body size.

On the other hand, if the modern Japanese are descended from the Yayoi and not the Jomon people, the change in tooth size would amount to a reduction of $2.5 \%$ which is comparable to the Gallo-Roman-to-modern French and Romano-British-to-modern English changes that occurred over roughly the same period of time. If we were to base our conclusions solely on a consideration of tooth size, this is what we would maintain, and it fits well with the most recent and sophisticated analysis of craniofacial metrics (Yamaguchi, in press). But one could argue that if one were to concoct a mixture of $70 \%$ Yayoi and 30\% Jomon, the result would be just what we see in modern Japan.

Now the question arises: which of these views is correct? For a number of reasons, the first of these possibilities is the least likely. For related reasons, the second must also be questioned as the sole explanation. But, if we were to turn exclusively to the third possibility suggested above, then that would mean that no change had occurred over the last 2000 plus years. In the light of what can be shown for other parts of the world, this too seems questionable. We are left with some sort of combination of the second and third possibilities namely a mixture of Jomon and Yayoi and some amount of continuing dental reduction. At this point, an appraisal of dental metrics cannot tell us how much of which was involved, and the solution will have to await the future appraisal of other traits. It is in fact our cognizance of both published and unpublished information on a number of other traits that has led us to this view.

\section{The Ainu question}

Before we consider these "other traits," however, we should bring up the often-mentioned matter of the Ainu. No one questions the fact that they are the aboriginal inhabitants of the northeastern island of Hokkaido. On the other hand, what is their relation to the other groups in question, i.e., the Jomon, the Yayoi, and the modern Japanese? Based strictly on tooth size, they are significantly smaller $(<0.01)$ than any of the groups under consideration. In fact, they have the smallest teeth of any population so far measured in all of Asia. The nearest group to them is the Jomon, being only $6 \%$ less reduced in dental size. If they were indeed associated with the oldest pottery tradition in the world, this is what would be predicted. The only flaw in the argument is the simple fact that the contemporary Ainu lack pottery (Watanabe, 1964, 1973). For the long-term use of pottery-related cooking techniques to have been responsible for the reduction manifest in the Ainu dentition, one would have to argue that they must have once possessed pottery which they gave up in the recent past. If there were 
no other factors involved, this argument would seem strained to the point of being gratuitous.

\section{Observations on morphology}

There are, however, some other factors. The most recently analyzed of these is dental and involves morphology and not metrics. It was observed that the Ainu and the Jomon show greater resemblances to each other in aspects of dental morphology than either does to the modern Japanese, while the moderns display similarities to the Bronze Age Chinese of 3000 years ago (Turner, 1976, 1979; Turner and Hanihara, 1977).

The same thing is also true if the appraisal is made on the basis of craniofacial form, whether subjectively (Koganei, 1903, 1927, 1937) or on the basis of multivariate analysis (Howells, 1966; Yamaguchi, in press). All of these assessments support the view that the Ainu and Jomon form is essentially the same.

During the work that produced the measurements reported in the present paper, the accuracy of the assessments made by Koganei over a generation ago was compellingly reaffirmed. The complex of traits that he observed, and which evidently provides the basis for the multivariate pattern that has subsequently been shown, is immediately and visually obvious. Ainu and Jomon crania are characterized by low rectangular orbits, a marked swelling at glabella and a depression at nasion, high bridged nasal skeletons, and narrow sharp-edged piriform apertures with marked nasal sills and spines (Fig. 1).

Yayoi crania, on the other hand, are characterized by high round orbits, low-bridged nasal skeletons, and broad piriform apertures with indistinct skills (Fig. 2). In this respect, they bear a striking resemblance to the crania of the Chinese Neolithic. On the side, we note that composite cross-sectional areas of the teeth are not significantly different from the Yang Shao Neolithic (TS =1247). Nor, at the same time, are they different from the modern inhabitants of Harbin in Heilongjiang Province (Manchuria) in northeastern China (TS $=1248$ ) (Brace, et al., in press).

Finally, the Chinese Neolithic practice of incisor evulsion during early adolescence-presumably as an initiation rite (Kanaseki, 1960; Yen, 1973)-seems to have been introduced to Japan by the Yayoi people (Koganei, 1937), where it was taken over extensively by the indigenous Jomon. There is disagreement on this matter, and the view has been expressed that tooth evulsion was practiced in Jomon Ja- pan long before the coming of the Yayoi (Harunari, 1973). From an examination of the available specimens by the first author, however, no examples of tooth evulsion were noted among the few available Early Jomon individuals nor were any observed from the much larger Middle Jomon samples. Meanwhile, evulsion had been practiced extensively in Neolithic China. By Late and Latest Jomon, the evidence for evulsion suddenly becomes very widespread, but the overlap in time with the incoming Yayoi is so extensive that we agree with Koganei's suggestion that the Jomon may well have adopted what they regarded as the indications of a higher civilization from the invaders.

In summary, although the Yayoi entered Japan after the end of the Chinese Bronze Age, they looked predominantly like late representatives of the Chinese Neolithic, and had teeth that were significantly larger than the Bronze Age Chinese at An Yang in Henan (Brace, 1978). To the extent that they differed from typical Chinese Neolithic form, they did so by the presence of a hint of the rectangular in orbit form, an occasional swelling at glabella, and some tendency of nasal form to deviate from the low broad configuration that suggests a southern origin for the Chinese Neolithic (Brace et al., in press). All this would be compatible with the view that the incoming Yayoi absorbed an element of the resident Jomon on first contact. The presence of Jomon elements in Yayoi pottery suggests that cultural mixing took place as well ( $\mathrm{H}$. Kanaseki, personal communication).

As the Yayoi spread eastward in Honshu reaching its northern end by 300 A.D. (IkawaSmith, 1980:142), it would be reasonable to expect that further amounts of the indigenous Jomon were absorbed. Certainly it is our impression that modern Japanese skulls differ from the Yayoi by the occurrence of somewhat more elevated nasal skeletons and smaller jaws and teeth. While the reduction in tooth size could have been the result simply of the same trends visible elsewhere in the world, the changes in the details of nasal form are much easier to account for by the addition of a small but noticeable amount of Jomon to the characteristically broad and low-bridged Yayoi condition.

\section{The southern question}

The final matter for our discussion is the oftrepeated theme of the "southern element" in the make-up of the Japanese population. Tra- 

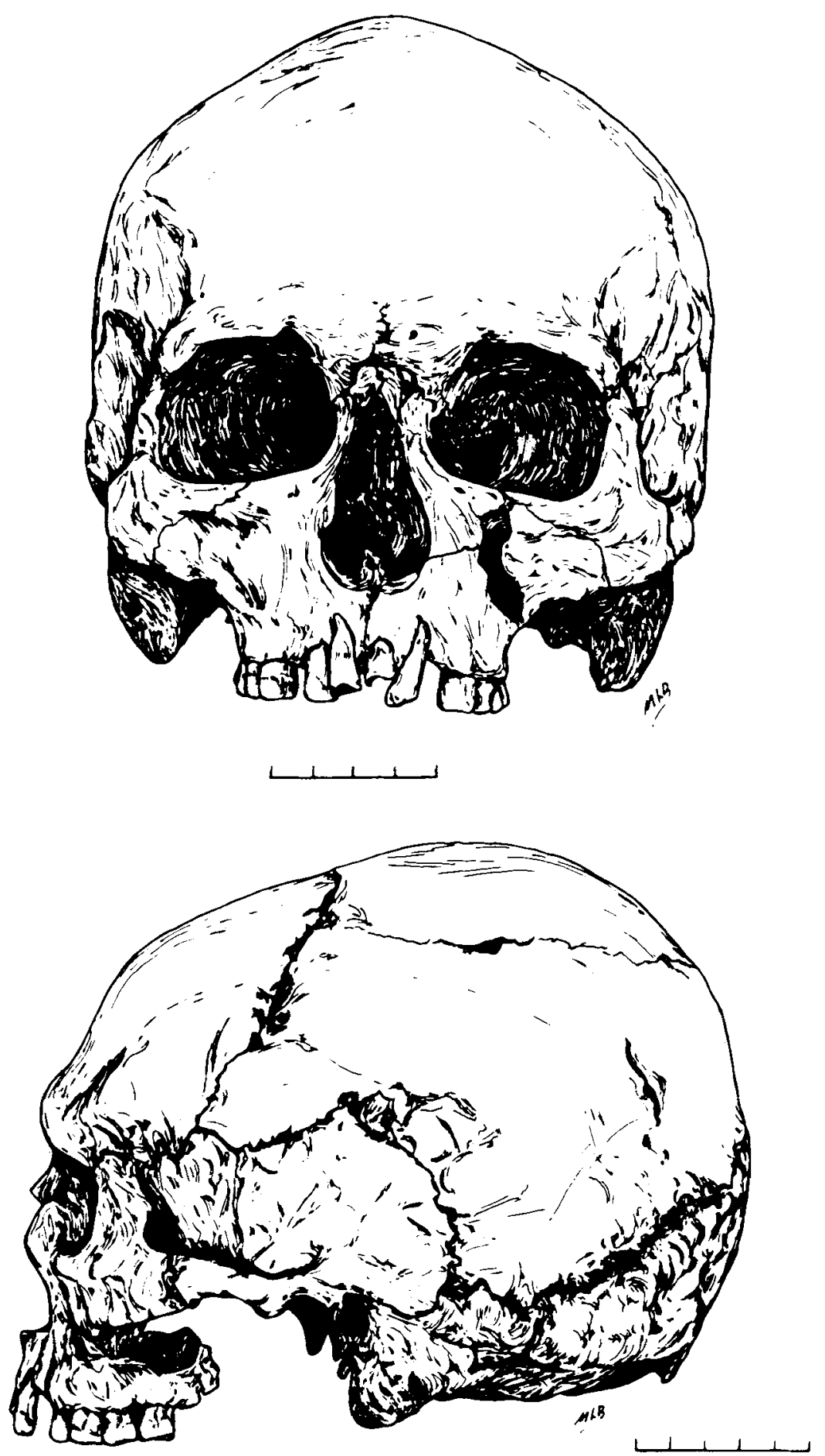

Fig. 1. A male Jomon skull, norma frontalis and norma lateralis. Drawn by Mary L. Brace from a photograph taken by Karen Rosenberg in the Laboratory of Physical Anthropology at Kyoto University. 

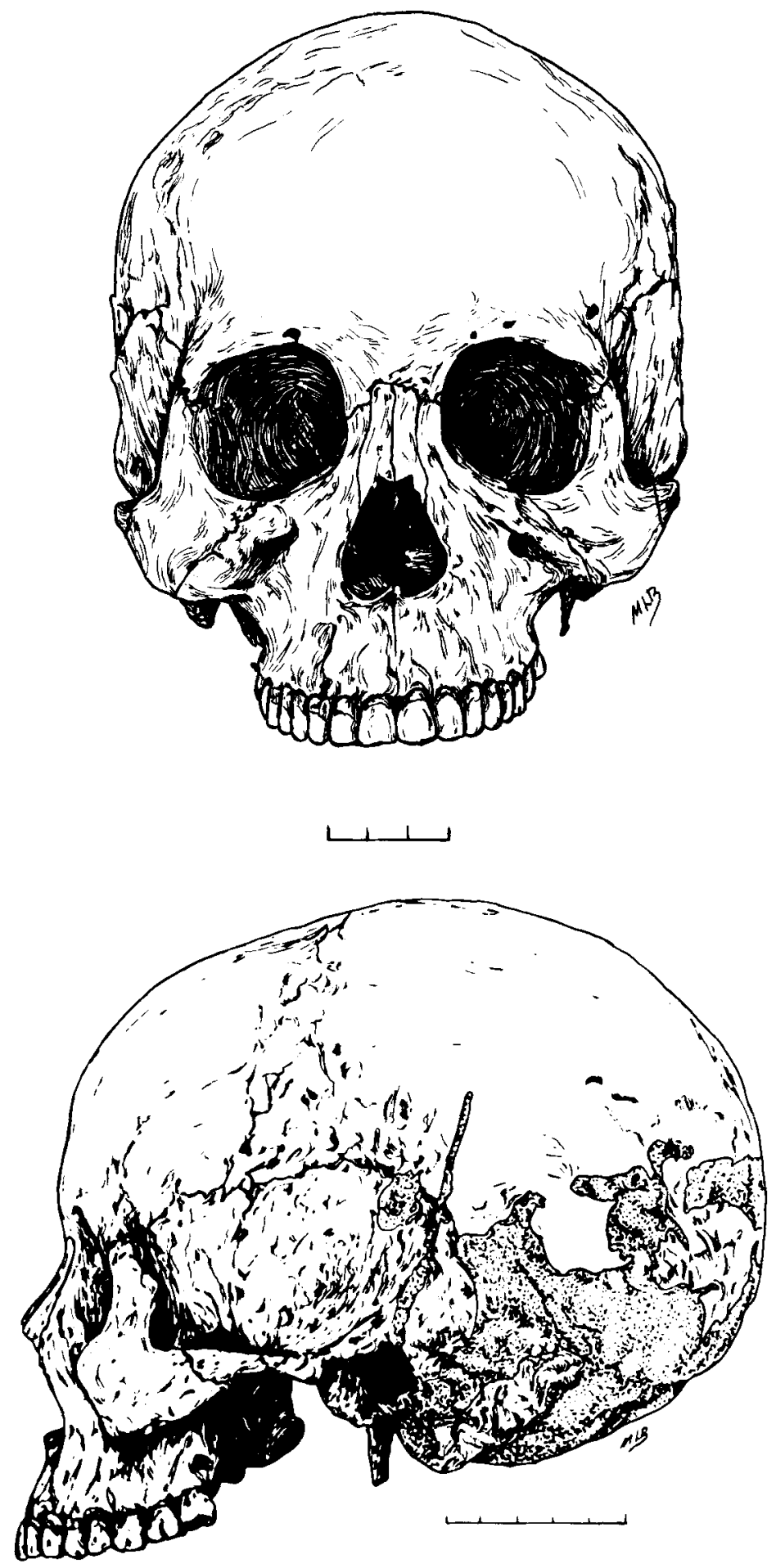

Fig. 2. A male Yayoi skull, norma frontalis and norma lateralis. Drawn by Mary L. Brace from a photograph taken by Karen Rosenberg in the Department of Anatomy at Kyushu University. 
ditions and cultural elements suggestive of a southern origin have been noted for more than a century (Morse, 1878; Koganei, 1937). In addition, more than one linguist has dealt with the possibility that the Japanese language has an Austronesian substratum to it (Murayama, 1972; Miller, 1974; Chew, 1978). Some have even suggested that the Ainu themselves represent a branch of the "Oceanic race" which migrated north from an original homeland that ranged from Sumatra to the Philippines (SaintMartin, 1872). The recent comparative assessment of dental morphology has also noted a simplification of occlusal features which resembles that in the Southeast Asian archipelago and has resurrected the idea of an early migration from insular Southeast Asia (Turner and Hanihara, 1977).

These are provocative and interesting ideas, and it would be premature to reject them out of hand, but there are two reasons that lead us to question the direction of the assumed movement. First, the high-bridged elongate and narrow nose characteristic of the Jomon and Ainu facial skeleton, as enshrined as the ideal of Samurai form depicted in Japanese art (Fig. 3 ), is quite unlike that found in groups that have had a long association with the moist tropics. Instead, such a configuration is more what one would expect of the long-time inhabitants of the drier portions of the world-especially the cold dry portions (Woo and Morant, 1934; Wolpoff, 1968; Carey and Steegmann, 1981).

The second reason for our skepticism, and one that is directly related to the data we present, is the fact that the dentition of the Jomon people of Japan 5000 years ago was so much smaller than that of the contemporary people of Southeast Asia that there is no way the latter could have been their source in any reasonable span of time. The preNeolithic people of Southeast Asia, while perhaps displaying a dental morphology similar to that seen in Jomon, had teeth that were 17\% larger (Brace and Vitzthum, in press). This means that, even with the rate of change of $1 \%$ per 1000 years, if the inhabitants of the two areas had a common source, they subsequently would have had to be living under different selective-force regimes for at least the previous 17,000 years. Jomon begins around 12,000 years ago and the pottery, at the beginning, was quite unlike that either in China (Chang, 1977) or anywhere farther south. For one thing, the earliest Jomon pottery, unlike that of Southeast Asia and despite its name, is not cord marked (Ikawa-Smith,

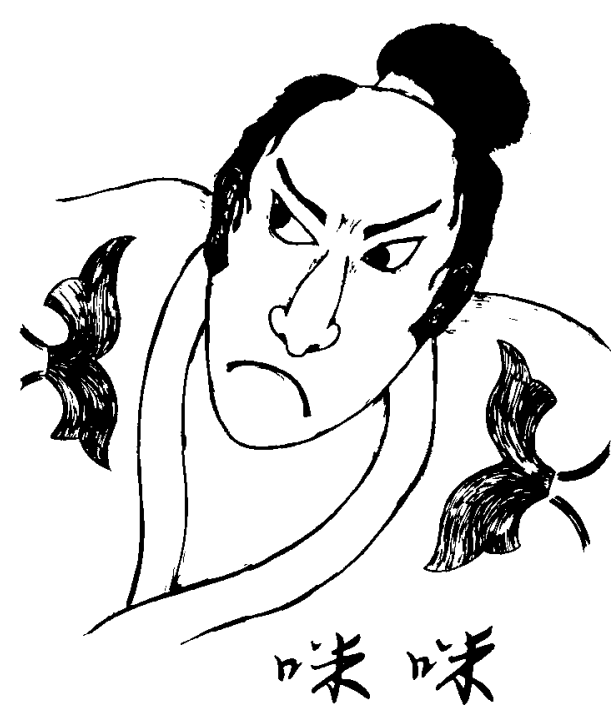

Fig. 3. A famous sixteenth century samurai, Musashi Miyamoto. Drawn by Mary L. Brace after an 1848 print by Kuniyoshi, Fig. 5 in Harris, 1974.

1976). If Southeast Asia really were the area of origin of the Jomon people, then it would have to have been on the order of 30,000 years ago or more. While this is not inconceivable, it has pushed the matter so far back in the past that the question cannot be tested by any of the evidence currently available. Furthermore, there is no archeological evidence in Southeast Asia to suggest that the conditions which led to dental reduction had been in operation for anywhere near long enough to have produced the amount of reduction visible in Jomon jaws and teeth.

\section{The Oceanic connection}

There is one last twist to the "southern question," and that is the issue of the possible tie with the peoples of Oceania. It has been noted that the Austronesians who spread into Oceania were characterized by a considerable degree of dental reduction. In New Zealand, the Marquesas and Hawaii, for example, summary tooth size was significantly smaller than that among modern Japanese (Brace and Hinton, 1981; Brace and Ryan, 1980). Until we tabulated the results of our work on the Japanese collections reported here, the only source of such reduction for which we had any evidence was in southern China (Brace, 1978). Now at least we can point to Jomon Japan as another possibility.

This leads us back to the observations on 
morphology which we used to strengthen our case for the affiliation between the Jomon and the Ainu on the one hand, and the Yayoi and the Chinese Neolithic on the other. The modern southern Chinese with the smallest teeth on the Asian continent display features of nose, orbit, and cranial morphology that look like reduced versions of the Chinese Neolithic. In Polynesia, however, the rectangular orbits, swelling at glabella, elevation of the nasal skeleton, and a series of other features look far more like the Jomon of Japan and not at all like the small-toothed inhabitants of the Chinese mainland. This may account for the interesting pattern obtained by Yamaguchi's use of multivariate statistics where the Ainu were distinguished from the Australian aborigines, but affiliated with Oceanic groups (Yamaguchi, 1967). Is it just possible that the Jomon of Japan and the Ryukyus were the source from which the ancestors of the Oceanians originally came? This would account for the Austronesian substrate in Japanese and would be compatible with the focus on marine resources and technology that enabled the ancestors of the Oceanic people to exploit the previously uninhabited islands of the Pacific.

This, however, is pure speculation. There are too many loose ends and unknowns to sustain such a radical departure from the traditionally accepted views. Our point in raising the matter, however, is to note that, although a recent southern origin for the Jomon is most unlikely in the light of the data we can marshall, there is yet a possibility that the Jomon configuration may have been part of an influence that went the other way-namely from north to south. The idea is not completely antic, and it at least deserves a serious hearing before it is summarily dismissed.

\section{CONCLUSIONS}

The substance on which this paper is based can be condensed to a single simple comparison, which is given in Fig. 4. The height of each bar is determined by the summary tooth size figure (square millimeters) found in the last row of Table 8. It is visually obvious that modern Japanese tooth size is smaller than that of the Yayoi of just over 2000 years ago. Even more obvious, modern Ainu tooth size is smaller than that of the Jomon from just over 2000 years ago to possibly several thousand years earlier. If the normal rate and pattern of recent human tooth size reduction had been occurring in Japan over the past several thousand years, then we could suggest that our data

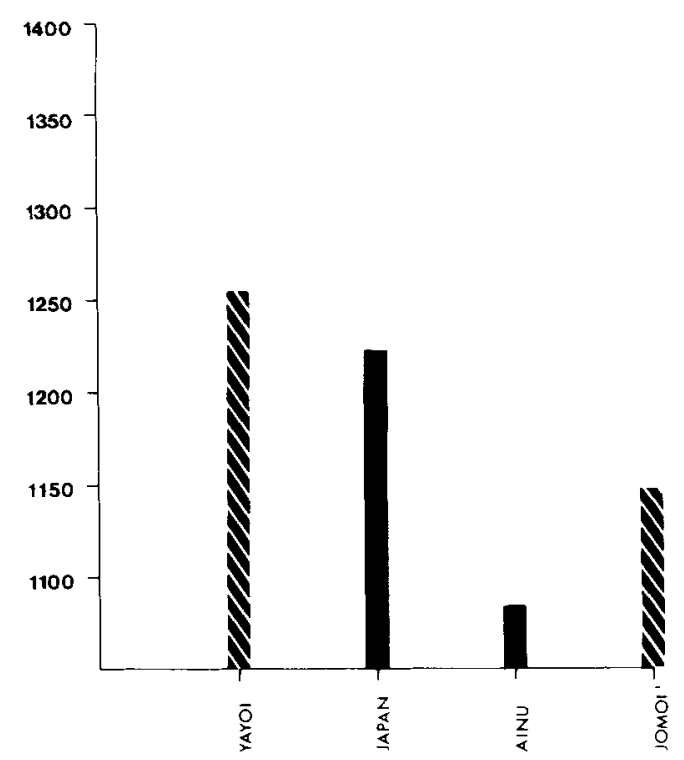

Fig. 4. Summary tooth size bars for Yayoi, modern Japanese, Ainu, and Jomon samples. The vertical axis represents square millimeters of total tooth size, and the values are taken from the last row in Table 8.

would support the view that the Yayoi were the ancestors of the modern Japanese, and the Jomon were the ancestors of the modern Ainu.

Considerations of matters of morphology sustain the latter suspicion, but the former must be subject to some modification. It seems clear from an assessment of naso-facial form that the transformation of the Yayoi into the modern Japanese configuration was accomplished in part by the incorporation of a noticeable Jomon component. At the cultural level, one could argue that the striking difference between Japanese cuisine and virtually all of the other culinary traditions of Asia reflects the survival of a major component from the Mesolithic. Sushi, sashimi, and dashi (stock made from dried seaweed and fish flakes) are central elements in Japanese gastronomy and have no counterparts elsewhere. The Japanese table setting of many small plates and bowls with no single major "dish," and the focus on yakimono (broiled), nabemono and nimono (simmered), and tsukemono (pickled) foods is also in marked contrast to other Asian gastronomic traditions (Keys, 1966; Tsuji, 1980). Many of the items favored in Japanese cuisine clearly derive from an intensive gathering form of subsistence in the past rather than from the traditions associated with an agricultural way of life. This 
is just one more demonstration of the fact that the assessment of population relationships and changes cannot be based on the consideration of a single dimension alone. A full scale treatment of this must await studies to be made in the future.

The Yayoi on their part, both in dental metrics and morphology, show clear ties with the Chinese Neolithic. The Jomon, on the other hand, present a configuration of nasal elongation and dental reduction that can best be accounted for by the long-term action of selective forces in situ in Japan. For this reason, then, a southern origin for the Jomon seems unlikely. And despite their lack of pottery, the modern Ainu are best regarded as the surviving representatives of Jomon Japan in whom the continuing trend of dental reduction has produced the smallest teeth in all of modern Asia.

\section{ACKNOWLEDGMENTS}

The work on which this paper was based was supported in part by the Committee on Scholarly Communication with the Peoples' Republic of China and the Horace H. Rackham School of Graduate Studies at the University of Michigan. The attempt to initiate a follow-up study of naso-facial form was denied support by the National Science Foundation. We are especially grateful to Prof. Kazuro Hanihara and Dr. Hiroko Koike of the University of Tokyo, Dr. Bin Yamaguchi and Dr. Yuji Mizoguchi of the National Science Museum in Tokyo, and to Prof. Jiro Ikeda and Dr. Masaki Nishida at Kyoto University for help with the collections. Dr. Hiroshi Kanaseki was especially helpful in making arrangements and dealing with the collections both in Kyoto and in Fukuoka City. Finally, we thank Patricia Bridges, Karen Rosenberg, and Virginia Vitzthum of the University of Michigan Museum of Anthropology for their extensive and invaluable role in handling and processing the dental measurements on which this paper is based. For critical reading and comments on earlier drafts of the manuscript, we are especially indebted to Prof. Hanihara and Dr. Yamaguchi, to Masao Nishimura of the University of Michigan Museum of Anthropology, to Gina L. Barnes of the Department of Archaeology, Cambridge University, and to G. Brace of the Institut Français du Pétrole Rueil Malmaison.

\section{LITERATURE CITED}

Armelagos, GJ, and Van Gerven, DP (1980) Sexual dimorphism and human evolution: an overview. J. Hum. Evol., 9(5):437-446.
Befu, H (1971) Japan: An Anthropological Introduction. San Francisco: Chandler.

Brace, CL (1963) Structural reduction in evolution. Am. Natural, 97:39-49.

Brace, CL (1967) Environment, tooth form and size in the Pleistocene. J. Dent. Res., 46 (Supplement to No. 5):809-816.

Brace, CL (1977) Occlusion to the anthropological eye. In MeNamara, JA (ed): The Biology of Occlusal Development. Craniofacial Growth Series Monograph No. 7. Ann Arbor, Michigan: Center for Human Growth and Development, pp. 179-209.

Brace, CL (1978) Tooth reduction in the Orient. Asian Perspect., 19(2):203-219.

Brace, CL (1979) Krapina, "classic" Neanderthals, and the evolution of the European face. J. Hum. Evol., 8(5):527-550.

Brace, CL (1980) Australian tooth-size clines and the death of a stereotype. Current Anthropo. 21(2):141-164.

Brace, CL (1981) Tales of the phylogenetic woods: the evolution and significance of phylogenetic trees. Am. J. Phys. Anthrop., 56(4):411-429.

Brace, CL, and Hinton, RJ (1981) Oceanic tooth-size variation as a reflection of biological and cultural mixing. Current Anthrop., 22(5):549-569.

Brace, CL, and Mahler, PE (1971) Post-Pleistocene changes in the human dentition. Am. J. Phys. Anthrop., 34(2):191-204.

Brace, CL, Mahler, PE, and Rosen, RB (1973) Tooth measurements and the rejection of the taxon "Homo habilis." Yearbook Phys. Anthrop., 16:50-68.

Brace, CL, and Ryan, AS (1980) Sexual dimorphism and human tooth size differences. J. Hum. Evol., 9(5):417-435.

Brace, CL, Shao X-q, and Zhang Z-b (in press) Prehistoric and modern tooth size in China. In Spencer, F (ed): The Origins of Modern Humans. New York: Alan R. Liss.

Brace, CL, and Vitzthum, V (in press) Human tooth size at Mesolithic, Neolithic and modern levels at Niah Cave, Sarawak. Comparisons with other Asian populations. Sarawak Museum J.

Carey, JW, and Steegmann, AT (1981) Human nasal protrusion, latitude, and climate. Am. J. Phys. Anthrop., 56(3):513-519.

Chang, K-c (1977) The Archaeology of Ancient China, 3rd ed. New Haven, Connecticut: Yale University Press.

Chew, JJ (1978) The prehistory of the Japanese language in the light of evidence from the structures of Japanese and Korean. Asian Perspect., 19(1):190-200.

Frayer, DW (1978) Evolution of the Dentition in Upper Paleolithic and Mesolithic Europe. Lawrence, Kansas: University of Kansas Publications in Anthropology, No. 10.

Gonda, K (1959) On the sexual differences in the dimensions of the human teeth. Jinruigaku Zassi 67:151-163.

Hanihara, K (1976) Statistical and comparative studies of the Australian aboriginal dentition. Bulletin Number 11, The University Museum, The University of Tokyo.

Hanihara, K (1977) Distances between Australian aborigines and certain other populations based on dental measurements. J. Hum. Evol, 6(4):403-418.

Harris, V (Translator) (1974) A Book of Five Rings, Musashi Miyamoto. Woodstock, N.Y.: Overlook.

Harunari, H (1973) Tooth extraction in ancient Japan. Kokogaku-Kenkyu 20(2):25-48.

Howells, WW (1966) The Jomon population of Japan: A study by discriminant analysis of Japanese and Ainu crania. Papers of the Peabody Museum of Archaeology and Ethnology (Harvard) 57(1):1-43.

Ikawa-Smith, F (1976) On ceramic technology in East Asia. Current Anthrop., 17(3):513-515.

Ikawa-Smith, F (1978) Introduction: The early Paleolithic tradition of East Asia. In Ikawa-Smith, F (ed): Early Paleolithic in South and East Asia. The Hague: Mouton, pp. 1-10. 
Ikawa-Smith, F (1980) Current issues in Japanese archaeology. Amer. Scientist 68(2):134-145.

Kanaseki, T (1960) The custom of teeth extraction in ancient China. Actes du VIe Congrès International des Sciences Anthropologiques et Ethnologiques, Paris. Tome I, pp. 201-205.

Kanaseki, T, and Kai, Y (1955) On the skeletal remains from the urn-burial sites of Yayoishiki-Age at Onobaru and Akinari, Ukiha-gun, Fukuoka-ken. Quart. J. Anthrop., 2(1):72-92. English summary pp. 72-73.

Kanaseki, T, Nagai, M, and Sano, H (1960) Craniological studies of the Yayoi-period ancients excavated at the Doigahama site, Yamaguchi prefecture. Quart. J. Anthrop., 7(supplement):1-36. English summary pp. 1-2.

Keys, JD (1966) Japanese Cuisine: A Culinary Tour. Rutland, Vermont: Tuttle.

Kintaka, K (1928) Anthropological studies on human bones from the shellmound of Yoshiko, Mikawa. J. Anthrop. Soc. Tokyo 43(supplement) Part I: The skulls. In Japanese.

Koganei, Y (1894) Beitrage zur physischen Anthropologie der Ainu. I. Untersuchungen am Skelet. Mittheilungen aus der Medicinischen Facultät der Kaiserlich-Japanischen Universität, 2:1-249,404.

Koganei, Y (1903) Messungen an chinesischen Soldaten Mitteilungen aus der Medicinischen Facultät der Kaiserlich-Japanischen Universität zu Tokyo, 6:123-145.

Koganei, Y (1927) Zur Frage der Abstammung der Aino und ihre Verwandtschaft mit anderen Völkern. Anthropologischer Anzeiger, 4(3):201-207.

Koganei, Y (1937) Zur Frage des "Südlichen Elementes" in Japanischen Volke. Zeitschrift fur Rassenkunde, 5(2):123-130.

Miller, RA (1967) The Japanese Language. Chicago: University of Chicago Press.

Miller, RA (1971) Japanese and Other Altaic Languages. Chicago: University of Chicago Press.

Miller, RA (1974) The origins of Japanese. Monumenta Nipponica, 29(1):93-102.

Miyabara, T (1916) An anthropological study of the masticatory system in the Japanese: The teeth. Dent. Cosmos, 58(7):739-749.

Morse, ES (1878) Traces of an early race in Japan. Pop. Sci. Monthly, 14:257-266.

Murayama, S (1972) Review of Japanese and Other Altaic Languages. Miller, RA (ed). Monumenta Nipponica $27(4): 463-467$

Ono, A (1957) Anthropological studies on the teeth of the Yayoi-age men from Mitsu, Kanzaki-gun, Saga-Prefecture. Quart. J. Anthropo., 4(1-4):423-462.

Pearson, $R$ (1977) Paleoenvironment and human settlement in Japan and Korea. Science 197:1239-1246.

Saint-Martin, V de (1872) L'ethnologie du grand archipel d'Asie. Une lacune à remplir dans la classification des races humaines. L'Année Géographique 9:90-97.

Sanui, Y (1960) Anthropological researches on the teeth of the prehistoric Yayoi-ancients excavated from the Doigahama site, Yamaguchi-Prefecture. Quart. J. Anthrop., 7(3-4):1095-1118. English summary pp. 1095-1097.
Semba, $T(1960)$ The studies on the bones of animals from the sites of Middle and Later Yayoi Period in the Iki Island, Nagasaki Prefecture, Japan. Quart. J. Anthrop., 7(1-2):190-235. English summary pp. 190-191.

Smith, P (1976) Dental pathology in fossil hominids: what did Neanderthals do with their teeth? Current Anthropol., 17(1):149-151.

Smith, $P$ (1977) Selective pressures and dental evolution in hominids. Am. J. Phys. Anthropo., 47(3):453-458.

Suzuki, H (1969) Microevolutional changes in the Japanese population from the prehistoric age to the present day. J. Faculty of Science, University of Tokyo, Section 5, 3(4):279-308

Tsuji, S (1980) Japanese Cooking: A Simple Art. New York: Kodansha.

Turner, CG, II (1976) Dental evidence on the origins of the Ainu and Japanese. Science, 193:911-913.

Turner, CG, II (1979) Dental anthropological indications of agriculture among the Jomon of central Japan. Am. J. Phys. Anthrop., 51(4):619-636.

Turner, CG, II, and Hanihara, K (1977) Additional feature of Ainu dentition. V. Peopling of the Pacific. Am. J. Phys. Anthropo., 46(1):13-24.

Ushijima, Y (1954) The human skeletal remains from the Mitsu site, Saga Prefecture, a site associated with the "Yayoishiki" period of prehistoric Japan. Quart. J. Anthrop., $1(3-4): 273-303$.

Watanabe, $H$ (1964) The Ainu: A study on ecology and the system of social solidarity between man and nature in relation to group structure. Journal of the Faculty of Science, University of Tokyo, Section 5 (Anthropology) 2(6):1-164.

Watanabe, H (1973) The Ainu Ecosystem: Environment and Group Structure. Seattle: University of Washington Press.

Williams, RC (1978) The probable mutation effect: neutral alleles and structural reduction. Hum. Biol., 50(2):173-181.

Wolpoff, MH (1968) Climatic influence on the skeletal nasal aperture. Am. J. Phys. Anthrop., 29(3):405-424.

Wolpoff, MH (1971) Interstitial wear. Am. J. Phys. Anthropo., 34(2):205-228.

Woo, TL, and Morant, GM (1934) A biometric study of the "flatness" of the facial skeleton in man. Biometrika $26: 196-250$.

Yamada, E (1932) The anthropological study of the Japanese teeth. Journal of the Nippon Dental Association 25(1):15-46; (2):101-132; (3):177-208; (4):255-286; (5):329-344; $\quad(7): 450-481 ; \quad(8) ; 528-560 ; \quad(9): 609-656$ (10):710-744; (11):774-812.

Yamaguchi, B (1967) A comparative osteological study of the Ainu and the Australian aborigines. Canberra: Aus. tralian Institute of Aboriginal Studies, Occasional Papers No. 10, Human Biology Series No. 2.

Yamaguchi, B (in press) A review of the osteological characteristics of the Jomon population in prehistoric Japan. Jinruigaku Zassi. J. of Anthrop. Soc. Nippon.

Yen, Y (1973) The Neolithic human skeletal remains from Hsi-Hsia-Hon. Kaogu Xuebao, 2:91-126. English summary p. 126. 